\title{
A Study on Opportunities and Challenges of Digital Marketing
}

\section{OPEN ACCESS}

Manuscript ID:

MGT-2021-08033427

Volume: 8

Issue: 3

Month: January

Year: 2021

P-ISSN: 2321-4643

E-ISSN: 2581-9402

Received: 28.10 .2020

Accepted: 04.12.2020

Published: 01.01.2021

Citation:

Poorani, D., et al. "A Study on Opportunities and Challenges of Digital Marketing." Shanlax International Journal of Management, vol. 8, no. 3, 2021, pp. 46-53.

DOI:

https://doi.org/10.34293/ management.v8i3.3427

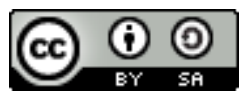

This work is licensed under a Creative Commons Attribution-ShareAlike 4.0 International License.

\section{Poorani}

Research Scholar, Department of Business Administration

RAAK Arts and Science College, Pondicherry, Tamil Nadu, India

\section{J. Vidhiya}

Research Guide, Department of Business Administration

Government Arts and Science College, Manalmedu, Tamil Nadu, India

\section{Santhosini}

Research Scholar, Department of Business Administration

Annamalai University, Chidambaram, Tamil Nadu, India

\begin{abstract}
Digital Marketing has emerged as extra well-known after the involvement of modern technologies in businesses. It has completely changed the historic advertising methods and compelled marketers to remain linked with their buyers or clients by using the net for promoting their products and services. Since the emergence of social media, industrial advertising teachers and entrepreneurs have additionally been intrigued by the influence of such media on the discipline. As social media lookup in the industrial marketing discipline has been of growing interest, this lookup tries to the challenges and possibilities in social media. This research offers some of the options to overcome the problems and analyzing the satisfactory method in a present-day scenario in the discipline and suggests directions for future development.
\end{abstract}

Keywords: Digital marketing, Customer, Advertising, Strategy, Challenges

\section{Introduction}

The quickest growing media outlet for advertising is the Internet. Compared to spending in other media, the expenditure on Internet advertising is experiencing tremendous growth. However, the whole expenditure on Internet marketing stays relatively small in contrast to other media. Yet, while Internet marketing is still a small player, its impact continues to extend every influential entrepreneur to shift a large element of their promotional budget to this medium. Two key reasons for this shift relaxation with the Internet's capability to 1) narrowly goal an advertising message and 2) song user response to the advertiser's message. The Internet offers many advertising picks with messages delivered thru websites or by way of an email. Handheld devices, such as cell phones, Personal Digital Assistants (PDAs) and other wireless devices, make up the developing mobile system market. Such devices allow customers to remain informed, acquire information and communicate with others, barring being tied to a physical location. While the mobile device market is only commencing to turn out to be a viable advertising and marketing medium, it may quickly provide a sizeable chance for marketers to attain customers at any time and any place. Also, with geographic positioning elements blanketed in more modern cellular devices, the medium can furnish marketers with the ability to target customers based totally on their geographic location. The most famous advertising and marketing delivery technique to cell units is through simple textual content messaging; however, over the next 
few years' multimedia, classified ads are predicted to become the dominant message format. Digital marketing plays a massive function in the latest pretty aggressive world. Companies, personalities, even voluntary or spiritual organizations use it in some structure - such as Event management, Image management, Internet marketing, etc. both to promote a product or promote a factor of view. Specifically, marketers will study customer behavior to apprehend the many factors that lead to an effect buy decision. Those who increase digital advertising strategies begin by figuring out applicable markets and analyzing the relationship between target customers and the product/service or brand. Often, in an strive to reap insights, marketers employ strategies borrowed from other disciplines.

Even time magazine focused on it in cover features, "Consumer Boom." If the customer, exposed to the advertisement, keeps it at the back of his mind or if in the case of non-durable makes a trial investment and is satisfied, it may result in putting the brand among the most - favored ones in his evoked set, as stated in the "Howard-Sheth model." Thus, there is a positive perception of advertisements for new brands and remainder advertisements for older brands. How the consumer uses this advertising communication provided by the marketer is a matter in consumer behavior's purview. Marketing people consider that advertising is effectively promoting the sales of a company's products and services. However, the relationship between advertising and sales is rather indirect.

The marketer should also measure the effectiveness of digital marketing, and in the face of results, obtained make qualitative changes in his marketing program. The appraisal of marketing programs should result in business becoming economically viable. The degree of its effectiveness vis-à-vis the amount spent on digital marketing cannot be measured directly as put rather helplessly by Wanamaker. The potential buyers make the buying decisions not only due to the digital marketing they see but also due to many other economic and social factors. The effectiveness of digital marketing is a function of several variables. The problem is that the organization cannot measure the impact of one variable alone.
Since digital advertising and marketing is broadly accepted as a huge marketing strategy, it is vital to format digital advertisements in new types and codes to make them more fantastic and available through famous media like e-mails, commercials via social sites like Facebook. Thus the difficulty of digital advertising is put to research from exclusive angles is evidenced by the literature review. This research finds out about adds new insightful inputs to the promotional techniques of advertising via digital sources. Starting in March 2020, we have entered a new technology recognized as COVID-19, accelerating what was once going to appear anyhow in the economy. All this has caused a shift in the world and as a consequence, brands have been shaken, forcing them to rethink their strategies. Within a few months, many companies will be in a large recession. This will spoil the glide of cash. From now on, digital advertising will be a good deal more applicable (Facebook, Google, Amazon, and YouTube) along with a digital approach and social media disaster plan. And as it is predicted, with a pandemic affecting more than 800,000 people globally, now not solely has health been affected, but the financial system has been severely impacted as well. That is why we want to contextualize the scenario as sincerely as viable and show you how a manufacturer can digitally adapt to the new world for the crisis's duration. Brands determining not to do advertising in times of disaster are the first brands that audiences will forget. Staying silent is now not a feasible option.

\section{Objectives}

- To the digital marketing tips during the crisis

- To know the opportunities in digital marketing.

- To identify the challenges in digital marketing.

- To ensure the successful techniques of internet marketing used today.

- To know the most preferred internet marketing approach.

- To know whether companies prefer internet marketing to traditional marketing.

\section{Scope of the Study}

Digital entrepreneurs display matters like what is being viewed, how frequently and for how long, 
income conversions, what content material works and doesn't work, etc. While the Internet is, perhaps, the channel most carefully related to digital marketing, others consist of wi-fi textual content messaging, mobile instant messaging, cell apps, podcasts, digital billboards, digital television and radio channels, etc. Digital advertising and marketing perform a goodsized position to serve the needs of the society in specific sectors, such as capital formation, the giant scale of production, industrialization, growth of exchange of commerce, etc.

1. It became a Professional Blogger

2. Digital marketing will ensure to earn with Affiliate Marketing \& AdSense

3. It helps to start Freelancing Services:

4. Guides to start its agency:

5. Become a YouTuber

6. Start the Dropshipping business:

\section{Review of Literature}

Internet marketing has been defined simply as 'achieving marketing objectives by applying digital technologies' (Chaffey et al., 2009). Digital marketing is the use of technologies to help shopping activities to improve customer knowledge by matching their needs (Chaffey, 2013). In the developed world, companies have realized the importance of digital marketing. For businesses to be successful, they will have to merge online with traditional methods for meeting the needs of customers more precisely (Parsons, et al., 1996). The introduction of new technologies has to create new business opportunities for marketers to manage their websites and achieve their business objectives (Kiani, 1998). Online advertising is a powerful marketing vehicle for building brands and increasing traffic for companies to succeed (Song, 2001). Expectations in producing results and measuring success for advertisement money spent, digital marketing is more cost-efficient for measuring ROI on an advertisement (Pepelnjak, 2008). Today, monotonous advertising and marketing techniques have given way to digital marketing. Also, it is so powerful that it can help revive the market and can create tremendous opportunities for governments to function in a more efficient manner (Munshi, 2012). Firms in Singapore have tested the success of digital marketing tools as being practical and useful for achieving results. (Teo, 2005). More importantly, digital marketing growth has been due to the rapid advances in technologies and changing market dynamics (Mort, et al., 2002). For digital marketing to deliver a result for businesses, digital content such as accessibility, navigation and speed are defined as the key characteristics for marketing (Kanttila, 2004). Another tried and tested tool for achieving success through digital marketing is the use of word-of-mouth WOM on social media and for making the site popular (Trusov, 2009). Also, WOM is linked with creating new members and increasing traffic on the website, which increases the visibility in terms of marketing. Social media, with an extraordinary example Facebook, has opened the door for businesses to communicate with millions of people about products and services and has opened new marketing opportunities in the market. This is possible only if the managers are fully aware of using communication strategies to engage the customers and enhancing their experience (Mangold, 2009). Marketing professionals must truly understand online social marketing campaigns and programs and understand how to do it effectively with performance measurement indicators. As the market dynamics worldwide are changing about the young audience accessibility to social media and usage. Strategic integration approaches must be adopted in an organization's marketing communication plan (Rohm \& Hanna, 2011).

For businesses, online reviews have worked well as part of their overall strategic marketing strategy (Zhang, 2013). Online service tools are more influential than traditional communication methods (Helm, et al., 2013). As part of the study, it is proven that users experience an increase in self-esteem and enjoyment when they adapt to social media, which is a motivating sign for businesses and marketing professionals (Arnott, 2013). Web experiences affect the mental process of consumers and enhance their buying decision online (Cetină, et al., 2012).

\section{Tips for Digital Marketing}

\section{Be strategic and act shortly}

Success is no longer only viewed in those who reply faster, however also in those who comprehend how to adapt to any situation. So it is important to 
research to manipulate and analyze the vast photo and make a good decision.

\section{A well-monitored manufacturer can detect a crisis earlier}

If it doesn't use Social Media Listening with the company always, it may additionally have a storm over the heads earlier than it can realize, so it is necessary now not only to reveal the company but also what takes place to the followers.

\section{Make a generic evaluation of communication}

To automate processes, we often strengthen all the content for our manufacturer to cover a specific period. However, it is necessary to do a full review when coping with a crisis in social networks to know if we have to make any changes.

\section{Respond any time}

Depending on the brand, on many occasions, the customers may additionally want a nearly immediate response, either to buy a product or service, as properly as to respond to the general popularity of the brand, it is vital to have a response model and continuous verbal exchange for letting users understand that the manufacturer is there for them.

\section{Prepare messages through analyzing one-of-a- kind scenarios}

Remember that in the course of a disaster, there are many altering situations, so it is essential that to put together with the group for all the occasions that might also occur and how they will work on Digital Marketing Strategies for disaster management. Maintaining a conversation is essential.

\section{Opportunities in Digital Marketing}

There are markets where classes are immediately impacted using patron behavior, such as retail, travel, technology, luxury, and entertainment. Nevertheless, as this arrives, it also brings with it opportunities; we mention some below: E-commerce (going from the physical keep to the digital one).

In the e-commerce projections of sales, we can see how the specialists point out the growth that this income channel is having.

This information is obtained from all the information on products or offerings that are ordered online, regardless of the charge method or form of requests, aside from journeys and tickets for events.
It should be cited that E-commerce for retail presents its facts primarily based on the US economy.

\section{Making a Brands difference}

During this world epidemic crisis, manufacturers stand out using adopting a correct marketing strategy in the course of hard times, showing thru solidarity what we are living through new and innovative proposals.

\section{Delivery}

All the companies that have this carrier have more suitable it even more. Since face-to-face attention has been limited, shipping service has been the step forward for many and its demand has increased like by no means before.

In our case, working with Papa John's Panama has made it's Omni channel Strategy eloquent along with, be in a position to take requests through its internet site or through the phone.

Papa John's Panama has come to be the warrior and remains in the race throughout COVID-19. It has positioned itself as the chief in online pizza sales while different organizations have failed, but PJ has a good social media crisis plan.

\section{Digital Transmission Media}

All the organizations in charge of digital tv, as correctly as on-line streaming, are capturing a massive audience considering that extra people are at home. The consumption of these structures is greater. It is time for the corporation to catch all these users.

In the case of Novey, its strategy has allowed them to proceed to project themselves digitally, in addition to their e-commerce and 25 shops all through the Panamanian territory. So with the high quantity of humans generating traffic on these platforms, it becomes now not only a sales opportunity; however, also a hazard to remain located in the consumer's mind.

\section{Online Car Sales}

While car income mirrors a massive drop in demand due to the COVID-2019 Pandemic, there are manufacturers taking gain of this to make a difference. An example of this is the Geely manufacturer in China, which incorporated a new provider providing users the opportunity to purchase a vehicle and be dispatched to their homes. Brands like Mercedes Benz and Tesla are now replicating 
this initiative, in addition to looking to expand it to other countries.

\section{Real Estate Additionally Adapts to Digital}

While some industries stop, others adapt; this is the case of the Real Estate Sector. And a sample, we can factor out the work of GoGetItleads; this digital real property agent takes the projects of their purchasers and gives them the opportunity of managing visits virtually so that humans can view the domestic of their dreams from the alleviation of their home. Manage from $\mathrm{A}$ to $\mathrm{Z}$ the digital technique of real property builders that continue to move despite the crisis. From the generation of the leads to the reservation of the property.

\section{Industry Transformation}

Influencers, celebrities, athletes, and others are presently turning to create stay content as part of their crisis administration method on social media.

Thanks to Instagram Live, many of them are working on their brand, clearly, due to the excessive tuning ratings that these moments get hold of and that approves them to keep their communities active.

This style is even more recent, so not solely businesses; however, non-public brands have become extra current in their digital accounts. More people want to stay energetic for the duration of these restricted times. An example of this is Power Club Panama, one of the most famous health club chains, which as a phase of its advertising and marketing strategy in times of disaster is instructing online classes (even when they stopped charging membership) so that their followers, as correctly as different users, stay energetic from their homes.

On other hand, for lovers of art \& history, some museums have opened their doors to public (virtually); an eg. of this is Museum of the Palace of Fine Arts presents a digital tour just a click away.

\section{Challenges for Entrepreneurs}

\section{Creating Consistent Branding}

Branding is one of the most vital factors in marketing. With so many messages tossed in consumers' faces day after day, it's integral to create a recognizable, relevant brand. Without consistent branding, the business turns into just some other faceless title in a sea of ads.
How do you strengthen a sturdy brand? By paying interest in the details. Everything from font and colorings to voice and style impacts the way the business is perceived. Keep these factors identical across all platforms and in all messages, and well on the way. A Brand Guidelines report will help ensure all advertising agencies, contractors, or new personnel recognize precisely.

\section{Generating Traffic and Leads}

Generating site visitors and leads looks to get harder, alternatively of simpler, as more significant platforms emerge as available. Many commercial enterprise owners spend all their time targeted on social media, sharing dozens of posts a week besides any variety of returns. It's frustrating, mainly when it appears to work for other brands. To get people fascinated in what to say, the first need to create a content audience in reality wants. Before it can do that, it must recognize the goal audience. Develop buyer personas based on surveys with customers, market research, and any different records can get the palms on.

- A sturdy lead generating an offer, like an infographic or digital guide, focused on a unique customer persona.

- A landing web page where plausible customers will fill out a structure to download the offer.

- A follow-up email to grant them the offer as quickly as they need it.

- A lead nurturing email collection to continue to engage with the information and construct belief, so they're geared up to buy product or service.

\section{Managing Website}

When done right, the internet site attracts visitors, converts them, and approves to make income even while you sleep. It's no surprise managing websites is one of the most considerable limitations modernday marketers face. Need the internet site to attract, nurture, and convert leads. Otherwise, it is nothing more significant than a brilliant golden toilet: a necessity you have thrown cash into. It's gone to waste and no longer serving its purpose. Most entrepreneurs recognize the significance of their website. However, they nevertheless conflict with the execution of it. Website troubles can range from growing lyrical content to designing an appealing 
site that is easy to navigate. Many companies, tiny businesses, simply don't have the time or staff to commit to website management.

\section{Securing an Effective Budget}

For many companies, there's simply now not an awful lot of wiggle room in the budget. And extra frequently than not, advertising and marketing aren't deemed a major priority for which resources are provided. However, reducing the marketing price range is like turning off an open sign. The commercial enterprise will by no means develop besides it. To justify spending money on marketing, you want to prove that what you're doing works. Track ROI and don't be afraid to strive for new things when the historical ones no longer deliver results. If you work with an advertising and marketing agency, ask for reports near the cease of the yrs. to demonstrate how money is going to top use.

\section{Understanding Tools and Technology}

Deciding on the right tools, technology, and software program for the enterprise can be difficult. With so many choices reachable and so many differing opinions on everyone, there appears to be no proper answer. At ROI Online, we stick to HubSpot. HubSpot is the leading all-in-one sales and advertising and marketing platform, and it blends seamlessly with the factors of the Growth Stack. Send emails automatically to workable clients relying on what forms they've filled out Keep a record of all leads' recreation on the website online Manage the deals and maintain song of sales year-round See precisely who has downloaded all lead generating gives on the website Create, post, and share out blogs. Much, plenty more There are different choices available, and for some, the value of HubSpot is out of their budget. Whatever you figure out to go with, simply be sure the group uses it persistently and gains all its uses.

\section{Creating the Right Content}

As we noted in our second point, generating site visitors and leads come from having great content. When brainstorming for the content material calendar for blogs, offers, emails, or social media posts, ask what troubles the target audience can solve. Always equipment the content material toward a unique problem of clients have. This will make it more enticing and more splendid beneficial. Next, consider the kind of contemporary content customers wants. Blog posts versus videos, for example.

\section{Finding the Best Marketing Talent}

A predominant problem for many enterprise proprietors and marketing managers is discovering good human beings to be part of their team. But often, hiring full-time advertising authorities isn't feasible. So rent the less expensive option. Like with net design, the commercial enterprise's high-quality guess can also be to partner with an advertising and marketing agency. These agencies rent great execs for each place of marketing. From writing exquisite content material to managing social media and beyond, they've received covered. If you decide to go in-house, utterly vet the applicants. Choose any individual with a bit of trip in content material introduction and design, as they may be in a position to support the commercial enterprise greater correctly than anybody who solely focuses on one area.

\section{Determining Marketing ROI}

Measuring the ROI (return on investment) of advertising projects is the most environmentally friendly way to determine the effectiveness of every campaign launch. It's additionally a sure-fire way to reap a larger advertising budget. Yet, it's one of the most challenging matters to do. To best measure ROI, you need to shut the loop between advertising and marketing things to do and sales results. There are several types of equipment reachable to assist in doing merely that, from marketing software program to CRM solutions. HubSpot is a perfect tool for this, and software program like MailChimp and Infusionsoft can also be beneficial.

\section{Training the Team}

Every worker ought to be accurately trained, and the advertising team is no exception. If selected to appoint a full- or part-time marketing staff, it's crucial to provide thorough education even if they're experts in their field. To do this, begin by evaluating the levels of expertise, strengths, and weaknesses of every group member. This gives you a beginning point and lets you comprehend where to invest the coaching time and money. Kolbe test is an exceptional aid for determining the place personnel shine and where they may have room for improvement. 
Next, have the group members set private growth goals for each quarter. These goals might include getting certifications in their place of expertise, studying a new advertising and marketing book, or watching a webinar. If schooling is a precedence at the workplace, it suggests extra in all likelihood to hire human beings interested in private increase and development.

\section{Facilitating Increased Customer Engagement}

All too often, entrepreneurs are compelled to spend so plenty of time and strength on acquiring new leads that they, by chance, neglect current customers. This is a big mistake because present clients have the practicable to supply additional income and referrals. So how does it hold human beings coming again for more? Devote particular assets to enticing modernday customers. Implement a consumer engagement design that can be effortlessly automated while concurrently offering perks for loyal customers. The diagram should encompass a customer delight survey sent out each year, a thank-you bundle (with branded cups or t-shirts) for every new client, distinct reductions for loyal customers, or a rewards program.

\section{Conclusion}

The motive of the study is to highlight digital advertising and marketing and its challenges. The find out about seeks to provide the ability to visualize how digital advertising strategies are formulated and perceived with the aid of customer segments. A standardized digital advertising method is more easily produced for products in which humans share common purchaser behaviors than for products used in culturally unique ways. For instance, patron high-tech items (computers, cell phones) can also be genuinely comparable throughout cultures, whereas food is usually viewed as bump-off in common and idiosyncratic ways. Beauty-related product commercials can also be more effortlessly standardized than extra culture-specific gadgets such as meals or cars because they center attention on comparable wishes for beauty amongst a shared audience. Indian consumers have continually been open to the thinking of trying new products. With the socio-economic adjustments taking vicinity and expanding the number of nuclear households and properly as twin-income families, there is a dramatic increase in the family and disposable incomes. To cater to their needs, marketers are introducing new and superior products and positioning them to appeal to goal customers. Not every digital initiative will work for every organization, and it is essential to assess functionality and ability for a trade earlier than deploying a digital strategy. In general, though, the extra holistic the initiative, the larger the chance of success. We trust that those who act holistically and act now stand to gain the best aggressive advantage.

\section{References}

Barska, Anetta, and Janusz Śnihur. "Senior as a Challenge for Innovative Enterprises." Procedia Engineering, vol. 182, 2017, pp. 5865.

Bhatia, Puneet Singh. Fundamentals of Digital Marketing, Pearson, 2017.

Bostanshirin, Soheila. "Online Marketing: Challenges and Opportunities." Proceedings of SOCIOINT14 - International Conference on Social Sciences and Humanities, 2014, pp. 783-792.

Cook, Glenn. "Customer Experience in the OmniChannel World and the Challenges and Opportunities this Presents." Journal of Direct, Data and Digital Marketing Practice, vol. 15, 2014, pp. 262-266.

Didner, Pam. Global Content Marketing, McGrawHill Education, 2014.

Gurău, Calin. "Integrated Online Marketing Communication: Implementation and Management." Journal of Communication Management, vol. 12, 2008, pp. 169-184.

Huotari, Lauri, et al. "Analysis of Content Creation in Social Media by B2B Companies." Journal of Business \& Industrial Marketing, vol. 30, no. 6, 2015, pp. 761-770.

Jones, Paul, et al. "An Exploration of the Attitudes and Strategic Responses of Sole-Proprietor Micro-Enterprises in Adopting Information and Communication Technology." International Small Business Journal, vol. 32, no. 3, 2014, pp. 285-306.

Kumar, Mahesh, and K.B.Jincy. "Digital Marketing: Challenges and Opportunities." Paripex - 
Indian Journal of Research, vol. 6, no. 11, 2017, pp. 117-119.

Meiners, Norbert H., and Bernd Seeberger. "Marketing to Senior Citizens: Challenges and Opportunities." The Journal of Social, Political, and Economic Studies, vol. 35, no. 3, 2010, pp. 293-328.

Morris, Neil. "Understanding Digital Marketing: Marketing Strategies for Engaging the Digital Generation." Journal of Direct, Data and Digital Marketing Practice, vol. 10, 2009, pp. 384-387.

Pitta, Dennis. "The Challenges and Opportunities of Marketing to Millennials." Journal of Consumer Marketing, vol. 29, no. 2, 2012.

Quinton, Sarah, and Sally Harridge-March. "Relationships in Online Communities: The Potential for Marketers." Journal of Research in Interactive Marketing, vol. 4, no. 1, 2010, pp. 59-73.

Rowley, Jennifer. "Just Another Channel? Marketing Communications in e-Business." Marketing
Intelligence \& Planning, vol. 22, no. 1, 2004, pp. 24-41.

Simmons, G.J. "i-Branding: Developing the Internet as a Branding Tool." Marketing Intelligence \& Planning, vol. 25, no. 6, 2007, pp. 544-562. Taiminen, Heini Maarit, and Heikki Karjaluoto. "The Usage of Digital Marketing Channels in SMEs." Journal of Small Business and Enterprise Development, vol. 22, no. 4, 2015, pp. 633-651.

Truong, Yann, and Geoff Simmons. "Perceived Intrusiveness in Digital Advertising: Strategic Marketing Implications." Journal of Strategic Marketing, vol. 18, no. 3, 2010, pp. 239-256.

Veit, Daniel, et al. "Business Models." Business \& Information Systems Engineering, vol. 6, 2014, pp. 45-53.

Yasmin, Afrina, et al. "Effectiveness of Digital Marketing in the Challenging Age: An Empirical Study." International Journal of Management Science and Business Administration, vol. 1, no. 5, 2015, pp. 69-80.

\section{Author Details}

D. Poorani, Research Scholar, Department of Business Administration, RAAK Arts and Science College, Pondicherry, Tamil Nadu, India

Dr. J. Vidhiya, Research Guide, Department of Business Administration, Government Arts and Science College, Manalmedu, Tamil Nadu, India, Email ID vidhiyajawahar2007@gmail.com

Santhosini, Research Scholar, Department of Business Administration, Annamalai University, Chidambaram, Tamil Nadu, India 